\title{
ARTIGOORIGINAL
}

\section{O "DESCORTINAMENTO" DAS VULNERABILIDADES DA POPULAÇÃO LGBTQIA+ DIANTE A PANDEMIA DE CORONAVÍRUS}

DOI: 10.22289/2446-922X.V6N2A23

Fabiano Saft Silva ${ }^{1}$

\section{RESUMO}

O presente artigo propõe uma revisão sistemática com base em pesquisas que abordam os impactos da pandemia de Coronavírus (COVID-19) na população LGBTQIA+, explicitando que trata-se de uma crise dentro de uma crise. O "descortinamento" de opressões e outras formas de violência fica claro ao passo que o número de problemas de saúde mental agravou-se potencialmente para a maioria deste segmento, que encontram-se obrigados a conviver com familiares que não legitimam as suas orientações sexuais e identidades de gênero. Trabalho, renda e solidão também são questões que encontram-se agravadas diante o cenário de isolamento social para grande parte da população LGBTQIA+. Os resultados encontrados mobilizam reflexões acerca do papel da Psicologia na luta por Direitos Humanos e acesso integral a serviços de saúde para essa população, que convive com a privação destes espaços. O diálogo intersetorial com outras áreas do conhecimento também mostra-se crucial a fim de elaborar ações estratégicas e afirmativas, em prol da população vítima de violência.

Palavras-chave: Psicologia; Saúde; LGBT; Pandemia; Direitos Humanos.

\section{THE “DISCOVERY” OF THE VULNERABILITIES OF THE LGBTQIA + POPULATION BEFORE THE CORONAVIRUS PANDEMIC}

\section{ABSTRACT}

This article proposes a systematic review based on research that addresses the impacts of the Coronavirus pandemic (COVID-19) on the LGBTQIA+ population, explaining that it is a crisis within a crisis. The "unveiling" of oppression and other forms of violence is clear, while the number of mental health problems has potentially worsened for the majority of this segment, who are obliged to live with family members who do not legitimize their sexual orientations and gender identities. Work, income and loneliness are also issues that are aggravated by the scenario of social isolation for a large part of the LGBTQIA+ population. The results found mobilize reflections about the role of Psychology in the fight for Human Rights and full access to health services for this population, who live with the deprivation of these spaces. The intersectoral dialogue with other areas of knowledge is also crucial in order to develop strategic and affirmative actions, in favor of the population that is victim of violence.

Keywords: Psychology; Health; LGBT; Pandemic; Human Rights.

\footnotetext{
${ }^{1}$ Endereço eletrônico de contato: fabianosaft@gmail.com

Recebido em 02/07/2020. Aprovado pelo conselho editorial para publicação em 30/11/2020.
}

Rev. Psicol Saúde e Debate. Dez., 2020:6(2): 346-355. 


\section{EL “DESCUBRIMIENTO” DE LAS VULNERABILIDADES DE LA POBLACIÓN LGBTQIA + ANTE LA PANDEMIA DEL CORONAVIRUS}

\section{RESUMEN}

Este artículo propone una revisión sistemática basada en una investigación que aborda los impactos de la pandemia de coronavirus (COVID-19) en la población LGBTQIA+, explicando que es una crisis dentro de una crisis. La "revelación" de la opresión y otras formas de violencia es clara, mientras que el número de problemas de salud mental ha empeorado potencialmente para la mayoría de este segmento, quienes están obligados a vivir con familiares que no legitiman sus orientaciones sexuales y identidades de género. El trabajo, los ingresos y la soledad también son problemas que se ven agravados por el escenario de aislamiento social para una gran parte de la población LGBTQIA+. Los resultados encontrados movilizan reflexiones sobre el papel de la psicología en la lucha por los derechos humanos y el pleno acceso a los servicios de salud para esta población, que vive con la privación de estos espacios. El diálogo intersectorial con otras áreas del conocimiento también es crucial para desarrollar acciones estratégicas y afirmativas, a favor de la población que es víctima de la violencia.

Palabras clave: Psicología; Salud; LGBT; Pandemia; Derechos humanos.

\section{INTRODUÇÃO}

A pandemia de Coronavírus (COVID-19) "descortinou" vulnerabilidades comuns à população LGBTQIA+, tais como trabalho e renda, saúde mental, direito à vida e violação às suas mais diversas formas de existências. Antes de iniciar a discussão proposta, é importante frisar que estamos falando de uma população bastante diversa, e tal como as cidades brasileiras, desigual. As violências às quais este segmento social estão atreladas, entretanto, muitas vezes atravessam essas diversidades e fazem-se, da mesma forma, presentes no seu cotidiano.

A violência intradomiciliar, neste sentido, não é diferente, sendo recorrente em suas narrativas o espancamento e diversas outras formas de sofrimento, tal como estupro corretivo, privação de prazeres, atrelada a uma constante vigilância por parte dos pais. Preterimento, silenciamento e distanciamento afetivo também precisam ser ressaltados, uma vez que a violência no ambiente familiar não pode ser reduzida ao plano físico.

Em um levantamento do Data Popular, que ouviu 1.264 brasileiros de cem cidades em todas as regiões do país, foi feita a seguinte pergunta: "Você aceitaria numa boa ter um(a) filho(a) homossexual?". O resultado desta pesquisa encontra a seguinte estatística: $37 \%$ dos brasileiros afirmam que não aceitariam um filho ou filha que fosse homossexual.

A ONU (Organização das Nações Unidas) reconheceu em um comunicado que a crise global do Covid-19 está potencializando as dificuldades da população LGBTQIA+ e pede a atenção dos

Rev. Psicol Saúde e Debate. Dez., 2020:6(2): 346-355. 
países à saúde e às violações de seus Direitos Humanos no contexto da pandemia. O comunicado destaca que ao ficar em casa, crianças, adolescentes e adultos LGBTQIA+ estão obrigados a uma exposição prolongada a membros da família que não os aceitam, o que aumenta as taxas de violência doméstica, agressões físicas e emocionais, assim como danos à saúde mental.

O presente artigo optou por uma revisão sistemática, onde foram analisados dados levantados por uma pesquisa que busca compreender os impactos da pandemia de Covid-19 para a população LGBTQIA+, que ouviu 10.065 pessoas das 5 regiões brasileiras. Esse estudo ajuda a sintetizar a evidência disponível na literatura sobre uma possível intervenção no cuidado direcionado à população em questão.

\section{MATERIAIS E MÉTODOS}

O método utilizado para realização do trabalho trata-se de um recorte de uma pesquisa realizada pelo coletivo \#VoteLGBT no contexto de pandemia mundial, onde visa expor um conjunto de dados provenientes dos impactos da pandemia de Covid-19 e o isolamento social para a comunidade LGBTQIA+. A pesquisa em questão busca compreender os impactos da pandemia de Covid-19 para a população LGBTQIA+ e ouviu 10.065 pessoas das 5 regiões brasileiras. Esse estudo, normalmente realizado fisicamente pelo coletivo \#VoteLGBT, precisou ser conduzido de maneira virtual, em função do isolamento social imposto pela pandemia.

\section{RESULTADOS}

Castañeda (2007), em um diálogo direto com as diversidades sexuais, relata que quando uma pessoa se reconhece homossexual, não existem benefícios visíveis. Diferente disto, confrontam-se com um futuro isolado que tendenciosamente trará conflitos com a família e a sociedade. Assumir-se homossexual, nesta perspectiva, não parece uma volta ao lar, mas, antes, um exílio.

Desta forma, a população que não se enquadra nos padrões cisheteronormativos está propensa a, inevitavelmente, no decorrer de suas expressividades, sofrer diferentes formas de violência. Os conceitos enrijecidos das cisheteronormatividades e as suas diferentes formas de opressão estão, sobretudo, presentes nos modelos familiares. Segundo o Coordenador de Saúde do Sistema Penitenciário, Dr. Paulo César Sampaio, cerca de 30 mil jovens estão aprisionados em clínicas porque a família não aceita a diversidade sexual e deposita naquela "ferramenta" a cura da homossexualidade (Lima, 2009). Importante ressaltar que o Conselho Federal de Psicologia, no uso de suas atribuições legais e regimentais, considerando que o Psicólogo é um profissional da saúde, 
expressa em seu Código de Ética que os Psicólogos não colaborarão com eventos e serviços que proponham tratamento e cura das homossexualidades (CFP, 1999).

Como sinaliza Castañeda (2007), existe uma forte tendência por parte da comunidade LGBTQIA+ em uma "guetificação" que, neste sentido, trata-se sobretudo de uma estratégia de sobrevivência mediante às violências direcionadas às diversas formas de vivências LGBTs, uma vez que os mesmos não sentem-se seguros em ambientes que costumam lhe ser hostis. Esta tendência acaba por legitimar e produzir lugares exclusivos para determinados indivíduos.

Silva (2016), em contrapartida, entende a ocupação da cidade como espaço público e fortalece a ideia de que acessá-la em sua totalidade significa um processo político, coletivo e de resistência às formas de violência discriminatória. Acrescenta ainda que na cidade contemporânea, os sujeitos políticos LGBTQIA+ e outros movimentos progressistas têm ajudado na luta que favorece o reconhecimento de todas as diversidades e as suas possibilidades de existência.

Harvey (2014), em suas reflexões acerca do "direito à cidade", nos ensina que o direito à cidade está, na verdade, correlacionado com a ideia de mudá-la e reinventá-la de acordo com as nossas mais profundas necessidades e subjetividades. Trata-se de um direito sobretudo coletivo, que reitere o princípio da liberdade de suas sociedades, uma vez que o que se chama de "subjetividade" é essencialmente social e assumida e vivida por indivíduos em suas existências particulares.

Apesar de as constantes lutas por acesso democrático às cidades, segundo Ribeiro (2016), grande parte da população LGBTQIA+ continua a optar por estes lugares "guetificados", por verem neles um espaço de libertação, que lhes resguardam das violências sofridas em seus bairros, trabalhos e sobretudo no seio familiar. Para Espinheira (1993), a rua é tida como o lugar da perdição e abandono. São inúmeras conotações negativas que repetem-se em relação a este espaço, enquanto a casa representa o resguardo da vida. O mar revolto e o porto seguro. Na rua podem-se viver múltiplas identidades. Não há lugar para o privado. Afinal de contas, a rua é coletiva.

Ainda nesse sentido, é possível perceber intenso sentimento de pertencimento, uma vez que o encontro com semelhantes contribui para o fortalecimento de suas identidades/orientações sexuais. É perceptível, nessa colocação, que tais lugares contribuem para a materialização de uma fraternidade e sobretudo acolhimento.

Em resumo, marcadas por diversas formas de violências, a população LGBTQIA+, em sua grande maioria, optou pela "autossegregação": resolveram, estrategicamente, agruparem-se entre si. Uma vez que o sentimento de libertação, acolhimento e pertencimento dependem de determinados espaços, nota-se que estes espaços estão cumprindo o papel de aceitar comportamentos que não são permitidos fora dali.

$\mathrm{O}$ contexto de isolamento social atrelado à pandemia de Coronavírus trouxe desafios e problemas para as cidades e isto reflete diretamente nas relações interpessoais. No contexto das Rev. Psicol Saúde e Debate. Dez., 2020:6(2): 346-355. 
pessoas LGBTQIA+ que não convivem com aceitação familiar, isto traduz-se de uma forma explícita: a redução de sua rede de apoio, atrelada ao impulsionamento da violência doméstica. O conceito de rede de apoio pode variar a depender do contexto, mas aqui, diante do que já foi exposto, trata-se exclusivamente destes espaços que estão atrelados à liberdade e destes encontros com semelhantes, que rotineiramente reforçam e autorizam as suas identidades. Além disso, o isolamento reforça uma convivência obrigatória com pessoas que não legitimam as suas existências.

Para muitas pessoas LGBTQIA+, a exclusão da família de origem implica na construção de novas estruturas, de novas fraternidades. A imposição do isolamento, atrelado à redução desta rede de apoio, resulta no retorno à solidão. Perder acesso a isto significa a falta de ambientes seguros para serem quem são. A rede de amigos é imprescindível para a população LGBTQIA+ que muitas vezes não encontram acolhimento na família. Espaços como universidades e ambientes de convívio social são muito mais do que lugares de estudo ou lazer. Significam ambientes onde podem sentirse seguros, física e emocionalmente.

Entre os dias 28 de abril e 15 de maio, mais de 10.000 pessoas responderam a um questionário promovido pelo coletivo "\#VoteLGBT" (2020), que buscava compreender os impactos da pandemia de Covid-19 para a população LGBTQIA+ e resultados expressivos foram encontrados.

Cinquenta por cento das pessoas que indicaram convivência familiar como a maior dificuldade do isolamento social tinham entre 15 e 24 anos. Ainda segundo o levantamento, 11,74\% dos entrevistados deparam-se com a solidão (\#VoteLGBT, 2020).

As pessoas que reportam a solidão como o maior problema do isolamento social estão nos grupos de 45 a 54 anos (60\% a mais de chance) e 55 ou mais ( $80 \%$ a mais de chance). Este é um dado importante, uma vez que as dificuldades e necessidades específicas do envelhecimento de pessoas LGBTQIA+ no Brasil são pouco discutidas, e segundo Araújo (2018), ainda há dificuldades encontradas para a discussão dessa temática, pois mesmo com o avanço nas pesquisas com grupo de idosos, ainda são escassas as publicações na área.

Nesta pesquisa, 42,72\% dos entrevistados relataram o aumento de problemas correlacionados à saúde mental como o maior impacto da pandemia. Aliado a isto, $54 \%$ das pessoas LGBTQIA+ afirmaram precisar de apoio psicológico. Em consonância, a mesma pesquisa reitera que o convívio familiar obrigatório, diante o isolamento social, tende a ser hostil para grande parte dessa população, sendo vítimas constantes de diversas formas de violência verbal, moral, psicológica e física.

Iran Giusti, Fundador da Casa 1, lar de Acolhimento à População LGBTQIA+ em São Paulo, relatou um expressivo retorno de ex-moradores (UNIVERSA, 2020). Sinalizou que este retorno acontece por conta das inúmeras demissões, uma vez que tratam-se de jovens que não tiveram a Rev. Psicol Saúde e Debate. Dez., 2020:6(2): 346-355. 
oportunidade de estudar, e os serviços em que estavam atuando eram essencialmente os que deixaram seus funcionários completamente desamparados. Guisti relata ainda que tem acolhido pessoas que vinham adquirindo maior independência, estudando e conseguindo reestabelecer, de alguma forma, laços familiares, situações que acabaram por ficar insustentáveis diante isolamento social.

O relatório do coletivo "\#VoteLGBT" expõe que 44,3\% das pessoas LGBTQIA+ tiveram suas atividades totalmente suspensas neste período de pandemia. Neste sentido, 10,6\% dos entrevistados pontuam que a falta de dinheiro é o maior impacto causado pela pandemia, e 7\% sinalizam a falta de emprego como potencializador de ansiedades e angústias. Além disso, 20,7\% dos entrevistados disseram não possuir renda e 21,6\% afirmaram estar desempregados. $O$ índice é quase o dobro se comparado com o de não ocupação da população brasileira, que é de 12,9\%, segundo a Pesquisa Nacional por Amostra de Domicílios (PNAD Contínua). Em um recorte étnicoracial, o mesmo levantamento expõe que LGBTs pretos, pardos e indígenas possuem $22 \%$ mais chance do que Brancos e Asiáticos de indicar a falta de dinheiro como a maior dificuldade da quarentena;

Em um relatório, a Associação Nacional de Travestis e Transexuais (ANTRA) revela que no primeiro trimestre de 2020 houve um aumento significativo na violência destinada à população Trans, mesmo sob as circunstâncias de isolamento social. Comparado ao ano anterior, segundo o mesmo relatório, constata-se um aumento de $39 \%$ no número de mortes. A pesquisa reitera que as mulheres trans trabalhadoras sexuais seguem exercendo seu trabalho nas ruas, sendo assim afetadas, sobretudo porque a maioria não conseguiu acesso às políticas emergências do Estado, devido a precarização histórica de suas vidas. Ainda segundo a ANTRA, aproximadamente $60 \%$ da população Trans não teve garantido o acesso à renda básica emergencial do Governo Federal, ou qualquer outro benefício na esfera governamental.

O modo como a família lida diante as diversidades de orientação sexual ou identidade de gênero estão intimamente correlacionadas a qualidade de vida e saúde mental da população LGBTQIA+. A violência doméstica já foi tida como a principal causa da morte de homossexuais (Prata, 2008). A rejeição ao indivíduo acarreta maior probabilidade de problemas de saúde mental como ansiedade, depressão ou ideação suicida. Marcelle Esteves, vice-presidente do Grupo ArcoÍris, acrescenta que por terem suas identidades deslegitimadas, a população Trans é recorrentemente vítima de violências mais severas.

O último dia 17/06/2020, já imersos às circunstâncias de isolamento social, e considerado o dia de Combate a LGBTfobia, Demétrio Campos, 23 anos, homem Trans, negro, não suportando mais as condições de violência às quais a sociedade lhe impunha, suicidou-se. Em suas redes sociais, Demétrio Campos constantemente propunha espaços de discussão sobre aceitação, dificuldades enfrentadas por ser um homem trans e depressão. 
Schulman (2009) descreve a família como a proteção da crueldade social, mas uma vez que a família representa esta crueldade, o papel tende a ser inverso e a vítima há de transformar a sociedade em seu refúgio. O questionamento mais pertinente, seguindo essa lógica, é: onde há de refugiar-se de toda a crueldade, sobretudo no contexto do isolamento social, a pessoa LGBTQIA+ vítima de violência?

Refletindo sobre contextos de crise econômica, é perceptível que as últimas décadas têm aumentado o tempo de coabitação de jovens com a família. Em contrapartida, os jovens LGBTQIA+ acabam indo no caminho oposto e saindo de suas casas mais cedo, mesmo antes de conquistar a independência financeira, e a necessária moradia para esse público torna-se emergencial. Deixa de ser uma demanda de atendimento restrito à esfera privada, adquirindo um caráter coletivo.

Daniliauskas (2016) observa que, apesar das Políticas Públicas desenvolvidas pelo Governo Federal no âmbito dos Direitos Humanos e Educação entre 2002 e 2010, período que apostava no controle e participação social, por meio de conferências nacionais, era nítida a pouca participação de jovens nesses espaços de debate.

Não obstante às grandes mídias, nos últimos tempos, terem dedicado mesmo que minimamente algum espaço de sua grade televisiva para assuntos pertinentes à comunidade LGBTQIA+ e mesmo que a LGBTfobia já tenha sido declarada crime pelo Supremo Tribunal Federal (STF), as violências continuam apresentando números viscerais e toda a vivência LGBTQIA+ permanece estagnada, "à margem". Viver ainda representa um desafio.

Segundo dados da Associação Brasileira de Familiares e Amigos de Portadores de Transtornos Afetivos (ABRATA), 5,8\% da população geral brasileira sofre de depressão e 9,3\% sofre de ansiedade. O levantamento do coletivo "\#VoteLGBT" reitera, entretanto, que para a população LGBTQIA+ os números são mais expressivos: $28 \%$ já tiveram diagnóstico de depressão, antes da quarentena. Destes, $47 \%$ foram classificadas com o risco de depressão no nível mais severo (\#VoteLGBT, 2020).

Como já sinalizado anteriormente, jovens LGBTQIA+ não estão presentes na construção de políticas públicas que os afetam diretamente, logo não podem contribuir com relatos sobre suas dificuldades e, sobretudo, necessidades. Daniliauskas (2016) reitera que estes não são ouvidos/as em suas críticas e sugestões nos conselhos nacionais. Reforça ainda que existem resistências internas no próprio governo e boicotes por grupos religiosos.

Como políticas públicas que dialoguem com os Direitos Humanos da população LGBTQIA+ poderiam ser implementadas com sucesso no combate ao preconceito e discriminação com tamanha falta de representatividade?

A pandemia age descortinando opressões: a ampliação do estigma destinado a população LGBTQIA+, as opressões cisheteronormativas e diferentes formas de violência são condutas que levam a impactos estruturais na vida e nos corpos dos sujeitos.

Rev. Psicol Saúde e Debate. Dez., 2020:6(2): 346-355. 


\section{CONSIDERAÇÕES FINAIS}

O novo coronavírus é um problema de saúde mundial, que tem trazido problemas e proposto ressignificações em vários aspectos da vida em sociedade, e diante do que já foi exposto, é possível dizer que abrange impactos na saúde que vai muito além da infecção. A população LGBTQIA+ sofre com problemas de saúde mental em números maiores que a média nacional. A depressão e a ansiedade manifestam-se potencialmente como consequência do convívio frequente com diversas formas de preconceito.

A pandemia age "descortinando" muitas destas vulnerabilidades. É preciso entender a origem deste problema. Entender as origens e mecanismos de perpetuação da LGBTQIA+fobia é o primeiro passo para combatê-la.

Ao passo que surgem, a passos lentos, as conquistas pelos Direitos Humanos, fica evidente que, no Brasil, ainda é escasso o conhecimento das necessidades em saúde mental da população LGBTQIA+. Estudos comprovam que a população em questão apresenta notável resistência à procura dos serviços de saúde, evidenciando o contexto discriminatório existente nestes espaços (Barbosa \& Facchini, 2009). Faz-se necessário, portanto, propor uma prática que busque enxergar o sofrimento humano em articulação com o seu plano de vida. Vida essa em suas infinitas manifestações: dor, sofrimento, medo, desamparo, desigualdades, iniquidades, etc.

Tanto o convívio social quanto o familiar são frequentemente fatores prejudiciais à saúde mental de pessoas LGBTQIA+. Diversas formas de preconceito e opressão transformam os ambientes mais comuns da existência em cenários de violência. Enquanto o discurso da cisheteronormatividade for predominante em nossa sociedade, haverá alguma forma de violência às pessoas LGBTQIA+.

Segundo Albuquerque et al. (2013), ainda são escassas as pesquisas que abordem o tema, o que dificulta o conhecimento acerca da real situação da saúde mental da população LGBTQIA+. Estudos que busquem conhecer tal relação, como forma de gerar dados que fomentem a formulação de outras políticas que efetivamente aproximem o grupo LGBTQIA+ dos espaços de saúde, mostram-se emergenciais, permitindo então fortalecer as políticas de equidade no enfrentamento a tais vulnerabilidades.

Abordar a importância da intersetorialidade e lutar pelas conquistas dos Direitos Humanos e de uma prática inclusiva em saúde faz parte de uma prática ética e comprometida em Psicologia, a fim de elaborar ações estratégicas e afirmativas-em prol de uma população vítima de violência, uma vez que todos esses fatores apresentados constituem nada menos do que uma forte expressão da privação dos Direitos Humanos. Perceber os impactos da pandemia para a saúde mental da 
população LGBTQIA+ faz-se uma reflexão crucial, viabilizando reconhecer que vivemos em um mundo de opressões, que nega direitos e extermina pessoas.

Os preconceitos nas práticas em saúde enrijecem barreiras, e tais preconceitos precisam ser revisitados, ressignificados. O preconceito destinado à população LGBTQIA+ não pode ser uma consoante nas práticas em saúde, a fim de transcendermos as barreiras impostas e superarmos os desafios. A responsabilidade do profissional com o paciente, levando em consideração também a dimensão social deste, respeitando a sua subjetividade e as suas demandas, deve ser uma atuação recorrente. A saúde é um direito de todos e a liberdade é terapêutica.

\section{REFERÊNCIAS}

Albuquerque, Grayce Alencar, Garcia, Cíntia de Lima, Alves, Maria Juscinaide Henrique, Queiroz, Cicera Monalisa Holanda Teles de, \& Adami, Fernando. (2013). Homossexualidade e o direito à saúde: um desafio para as políticas públicas de saúde no Brasil. Saúde em Debate, 37(98), 516-524. https://doi.org/10.1590/S0103-11042013000300015

Araújo, Ludgleydson Fernandes de, \& Carlos, Karolyna Pessoa Teixeira. (2018). Sexualidade na velhice: um estudo sobre o envelhecimento LGBT. Psicología, Conocimiento y Sociedad, 8(1), 188-205. https://dx.doi.org/10.26864/pcs.v8.n1.10

Associação Brasileira de Familiares e Amigos de Portadores de Transtornos Afetivos. (2020). Depressão e Transtorno Bipolar. Disponível: http://www.abrata.org.br/saudemental/depressao-e-transtorno-bipolar/

Associação Nacional de Travestis e Transexuais. (2020). ASSASSINATOS CONTRA TRAVESTIS E TRANSEXUAIS EM 2020.2 Disponível: https://antrabrasil.files.wordpress.com/2020/06/boletim-3-2020-assassinatos-antra.pdf

Barbosa, Regina Maria, \& Facchini, Regina. (2009). Acesso a cuidados relativos à saúde sexual entre mulheres que fazem sexo com mulheres em São Paulo, Brasil. Cadernos de Saúde Pública, 25(Suppl. 2), s291-s300. https://doi.org/10.1590/S0102-311X2009001400011

Castañeda, M. (2007). A experiência homossexual: explicações e conselhos para os homossexuais, suas famílias e seus terapeutas. São Paulo: Girafa.

Daniliauskas, M. (2016). Não se nasce militante, torna-se: processo de engajamento de jovens LGBT - panorama histórico na cidade de São Paulo e cenário atual em Paris. Tese de Doutorado, Faculdade de Educação, Universidade de São Paulo, São Paulo. doi:10.11606/T.48.2016.tde-06102016-142516. Recuperado em 2020-07-06, de www.teses.usp.br

ÉPOCA. (2013). 37\% dos brasileiros não aceitariam um filho homossexual, diz pesquisa. Disponível: https://epoca.globo.com/vida/noticia/2013/06/37-dos-brasileiros-nao-aceitariam-um-filhohomossexual-diz-pesquisa.html

ESPINHEIRA, Gey. (1993) A casa e a rua. In: Cadernos do CEAS, no 145, maio/junho, 1993. Salvador: Ceas.

Rev. Psicol Saúde e Debate. Dez., 2020:6(2): 346-355. 
HARVEY, David. (2012). O direito à cidade. Revista Lutas Sociais, São Paulo: PUCSP, 2012. Disponível: http://www4.pucsp.br/neils/downloads/neils-revista-29-port/david-harvey.pdf.

Lima, C. A. N. (2009). Direitos fundamentais LGBT. Disponível: http://carlosalexlima.blogspot.com/2009/11/no-brasil-existem-30-mil-jovens.html

ONU. (2020). UNAIDS e MPact manifestam preocupação com relatos de abuso contra pessoas LGBTI em meio à pandemia. Disponível: https://nacoesunidas.org/unaids-e-mpact-manifestampreocupacao-com-relatos-de-abuso-contra-pessoas-Igbti-em-meio-a-pandemia/

Pesquisa Nacional por Amostra de Domicílios Contínua - PNAD Contínua. (2020). Disponível: https://www.ibge.gov.br/estatisticas/sociais/habitacao/9171-pesquisa-nacional-por-amostrade-domicilios-continua-mensal. $\mathrm{html}$ ?edicao=28095\&t=destaques

Ribeiro, Andressa de Freitas. (2016). Espaço e sociabilidades: entre o beco e o gueto. Sexualidad, Salud y Sociedad (Rio de Janeiro), (24), 130-156. https://doi.org/10.1590/19846487.sess.2016.24.06.a

SCHULMAN, Sarah. (2009). Ties that Bind: Familial Homophobia and Its Consequences. New York: The New Press.

Silva, A. L. da, \& Santos, S. M. de M. dos. (2016). "O sol não nasce para todos": uma análise do direito à cidade para os segmentos LGBT.SER Social,17(37), 498-516. https://doi.org/10.26512/ser_social.v17i37.14259

UNIVERSA. (2020.) LGBTIs vivem acirramento de violência familiar em isolamento social. Disponível: https://www.uol.com.br/universa/noticias/agencia-brasil/2020/05/17/lgbtis-vivemacirramento-de-violencia-familiar-em-isolamento-social.htm

\#VOTELGBT. (2020). LGBT+ sofrem mais o impacto da pandemia. Disponível: https://www.votelgbt.org/pesquisas 